\title{
Um olhar da Psicopedagogia no contexto escolar inclusivo
}

\author{
A look at Psychopedagogy in the inclusive school context \\ Una mirada de la Psicopedagogía en el contexto escolar inclusivo
}

Recebido: 21/12/2021 | Revisado: 29/12/2021 | Aceito: 01/02/2022 | Publicado: 03/02/2022

\author{
Valéria Viviane Bianchi \\ ORCID: https://orcid.org/0000-0002-8106-7738 \\ Universidade Estadual do Paraná, Brasil \\ E-mail: valeria_vbianchi@hotmail.com \\ Dorcely Isabel Bellanda Garcia \\ ORCID: https://orcid.org/0000-0002-8613-2842 \\ Universidade Estadual do Paraná, Brasil \\ E-mail: dorcelygarcia@hotmail.com \\ Aline Roberta Tacon Dambros \\ ORCID: https://orcid.org/0000-0002-5540-5932 \\ Universidade Estadual do Paraná, Brasil \\ E-mail: aline_tacon@hotmail.com
}

\begin{abstract}
Resumo
A pesquisa desenvolvida tem como objetivo apresentar, especialmente aos pedagogos, o conhecimento da área de atuação da Psicopedagogia Institucional, além do trabalho e dos encaminhamentos do Psicopedagogo aos educandos que apresentam diagnóstico ou indicativo de Transtornos Funcionais Específicos (TFE). Trata-se de uma pesquisa bibliográfica e de campo de cunho qualitativo. A coleta de dados foi realizada por meio de questionário semiestruturado, com uma Psicopedagoga Institucional, que trabalha na Secretaria de Educação de um município no Norte do Paraná. A partir desses levantamentos foi possível conhecer com maior profundidade o trabalho do Psicopedagogo no âmbito escolar. O resultado da pesquisa teórica e de campo demonstra que as políticas públicas inclusivas, do Estado do Paraná, vêm sendo efetivadas neste município, embora com morosidade devido às condições objetivas. Conclui-se, também, que há necessidade de superar a barreira na comunicação entre os envolvidos no ambiente escolar, haja vista que, a função do Psicopedagogo Institucional é trabalhar, de forma reflexiva e com criticidade, com questões envolvidas no processo de organização do ensino e da aprendizagem, buscando encaminhamentos e pistas que auxiliem a superação dos obstáculos contextuais, levando em consideração a forma de aprender de cada um.
\end{abstract}

Palavras-chave: Psicopedagogia institucional; Transtornos funcionais específicos; Inclusão.

\begin{abstract}
The research developed aims to present, especially to pedagogues, the knowledge of the Institutional Psychopedagogy area of action, in addition to the work and referrals of the Psychopedagogue to students who have a diagnosis or indication of Specific Functional Disorders (SPT). This is a qualitative bibliographic and field research. Data collection was carried out through a semi-structured questionnaire, with an Institutional Psychopedagogue, who works at the Education Department of a municipality in the North of Paraná. From these surveys it was possible to know in greater depth the work of the Psychopedagogue in the school environment. The result of theoretical and field research demonstrates that inclusive public policies in the State of Paraná have been implemented in this municipality, albeit slowly due to objective conditions. It is also concluded that there is a need to overcome the barrier in communication between those involved in the school environment, given that the role of the Institutional Psychopedagogue is to work, in a reflective and critical way, with issues involved in the teaching organization process. and learning, seeking referrals and clues that help to overcome contextual obstacles, taking into account each one's way of learning.
\end{abstract}

Keywords: Institutional psychopedagogy; Specific functional disorders; Inclusion.

\section{Resumen}

La investigación desarrollada tiene como objetivo presentar, especialmente a los pedagogos, los saberes del área de actuación de la Psicopedagogía Institucional, además del trabajo y derivaciones del Psicopedagogo a los estudiantes que tienen diagnóstico o indicación de Trastornos Funcionales Específicos (TPS). Se trata de una investigación cualitativa bibliográfica y de campo. La recolección de datos se realizó a través de un cuestionario semiestructurado, con un Psicopedagogo Institucional, que actúa en el Departamento de Educación de un municipio del Norte de Paraná. A partir de estas encuestas se pudo conocer con mayor profundidad el trabajo del Psicopedagogo en el ámbito escolar. El resultado de la investigación teórica y de campo demuestra que las políticas públicas inclusivas del Estado de Paraná han sido implementadas en este municipio, aunque lentamente debido a condiciones objetivas. También se 
concluye que existe la necesidad de superar la barrera en la comunicación entre los involucrados en el ámbito escolar, dado que el papel del Psicopedagogo Institucional es trabajar, de manera reflexiva y crítica, las cuestiones involucradas en el proceso de organización de la enseñanza. y aprendizaje, buscando referentes y pistas que ayuden a superar los obstáculos contextuales, teniendo en cuenta la forma de aprender de cada uno.

Palabras clave: Psicopedagogía institucional; Trastornos funcionales específicos; Inclusión.

\section{Introdução}

Em um sistema educacional inclusivo, todos os alunos têm direito de estudarem no ensino regular, juntamente com seus pares, sendo estes públicos alvo da Educação Especial (EE) ou não. Neste contexto, ressaltamos o olhar da Psicopedagogia, que identifica os deficits de aprendizagem relacionados aos Transtornos Funcionais Específicos (TFE), que comprometem a aprendizagem e o desenvolvimento pleno do aprendiz. A atenção da Psicopedagogia está voltada para o processo de aprendizagem e busca constantemente meios para remover as barreiras/obstáculos na vida acadêmica dos indivíduos, seja de forma preventiva ou de intervenção. Para Carvalho (1999, p.60-61), "barreiras de aprendizagem são obstáculos que se impõem aos alunos, criando-lhes dificuldades no aprender”.

Os obstáculos fazem parte do cotidiano escolar, os mais comuns encontrados no trabalho psicopedagógico são: de interpretação, cognição, abstração, aquisição da matemática, leitura e escrita, entre outras. Nesse sentido, os profissionais da educação devem proporcionar um ambiente prazeroso para todos os aprendizes com foco nas suas potencialidades e não nas suas dificuldades, sejam elas temporárias ou permanentes.

No decorrer da pesquisa compreendemos que, conhecer a realidade escolar no contexto inclusivo é imprescindível para atuação de qualquer profissional da área de educação. O olhar desses profissionais engajados possibilita traçar um novo caminho para o desenvolvimento do processo de ensino e aprendizagem escolar.

O Psicopedagogo tem uma função auxiliar na aprendizagem dos alunos, muitas vezes, com dificuldades demonstradas e acirradas no decorrer dos anos iniciais, o que vem sendo percebido frequentemente nas salas de aula, resultando no fracasso escolar ${ }^{1}$.

As concepções teóricas contribuem para entender o fracasso escolar e aplicando-as em um contexto escolar inclusivo, com o intuito de evitar que os aprendizes sejam rotulados. Diante dessa situação, muitas vezes, de forma precipitada, o aluno é rotulado pelo seu comportamento e acaba em prejuízo físico ou emocional. Cada ser é único, traz consigo uma bagagem cultural e está envolvido com o processo de formação humana dentro da sua realidade. Procedimentos inadequados acabam reduzindo, dessa forma, suas potencialidades e requer observação e acompanhamento. Nesse sentido, Tuleski e Eidt (2010, p.539) corroboram a importância de analisarmos a qualidade das mediações estabelecidas em diferentes contextos sociais (como a família e a escola), considerando que o esfacelamento das relações entre os indivíduos se tornou uma característica da pós-modernidade.

Inserida nessa realidade, a qualidade das mediações tornou-se um dos principais focos de atenção em relação ao atendimento Psicopedagógico nas instituições escolares. Para elaboração deste artigo, após a apresentação introdutória, foi realizada a divisão em cinco seções, das quais as duas últimas dizem respeito à apresentação e análise de dados coletados em campo e às considerações finais.

Das seções que tratam das questões teóricas, a primeira refere-se à Psicopedagogia e ao processo de aprendizagem escolar. Traz um aprofundamento teórico sobre o papel da Psicopedagogia no âmbito escolar. A segunda discorre sobre Psicopedagogia Institucional, os TFE e as formas de intervenção.

\footnotetext{
1“O fracasso escolar é hoje um grande problema do sistema educacional brasileiro, surgiu nas últimas décadas do século XX, quando a maioria da população pertencente às classes populares teve acesso à escola” (Barros, Fontenele \& Conceição, 2012, p. 04).
} 
Em um terceiro momento, apresentam-se os documentos na perspectiva inclusiva, referente ao atendimento dos TFE, no Estado do Paraná e na sequência são expostos os aspectos legais a partir da Política Nacional de Educação Especial na Perspectiva da Educação Inclusiva (PNEEPEI) (2008)². Alguns documentos normativos constituem-se como primordiais para garantir o direito à escolarização a todos os educandos, seja com TFE ou com deficiência.

A quarta seção apresenta análise dos dados da pesquisa de campo realizada com uma Psicopedagoga Institucional, que atua na Secretaria de Educação de um município do norte do Paraná. Consideramos o ápice da pesquisa, conhecer por meio da pesquisa de campo o Atendimento Educacional Especializado (AEE), no município a ser pesquisado.

\section{Metodologia}

O objetivo deste estudo é apresentar, especialmente a pedagogos, o conhecimento da área de atuação da Psicopedagogia Institucional, além do trabalho e dos encaminhamentos do psicopedagogo aos educandos que apresentam diagnóstico ou indicativo de TFE. De acordo com a Instrução nº 07/2016 - SEED/SUED:

Os TFE referem-se à funcionalidade específica (intrínsecas) do sujeito, sem o comprometimento intelectual. Diz respeito a um grupo heterogêneo de alterações manifestadas por dificuldades significativas, tais como: na aquisição e uso da audição, linguagem oral, leitura, linguagem escrita, raciocínio, habilidades matemáticas, atenção e concentração. Os distúrbios de aprendizagem se referem a: dislexia, disortografia, disgrafia, discalculia e transtornos do déficit de atenção e hiperatividade - TDAH (Paraná, 2016b, p. 01).

A pesquisa, realizada por meio de pesquisa teórico-bibliográfica e de campo, é de caráter qualitativo e traz ações, informações, atuações, documentos e encaminhamentos sobre as redes de ensino regular e o processo de aprendizagem.

Referente à pesquisa de campo, segundo Gil (2008, p. 74), “As pesquisas deste tipo se caracterizam pela interrogação direta das pessoas cujo comportamento se deseja conhecer". A pesquisa bibliográfica é uma etapa fundamental em toda a pesquisa para adquirir o conhecimento necessário para o embasamento da mesma.

Segundo as autoras Marconi e Lakatos (2002 p. 43-44), a pesquisa bibliográfica, pode ser definida como “[...] o levantamento de toda a bibliografia já publicada, em forma de livros, revista, publicações avulsas e imprensa escrita. Proporcionando contato direto com tudo aquilo que foi escrito sobre determinado assunto".

E ainda, de acordo com Creswell (2010, p. 26), “[...] a investigação qualitativa gera diferentes concepções filosóficas, estratégias de investigação, métodos de coletas, análise e interpretação dos dados". A coleta de dados ocorreu por meio da aplicação de um questionário semiestruturado. "A entrevista é uma das técnicas de coleta de dados mais utilizada no âmbito das ciências sociais" (Gil, 2008, p. 128).

A respondente desse questionário foi uma Psicopedagoga Institucional, que trabalha na Secretaria de Educação de um município no Norte do Paraná. Segue o estudo com a apresentação da entrevista com a Psicopedagoga.

\section{Resultados e discussões}

\subsection{A psicopedagogia e o processo de aprendizagem escolar}

Diante do cenário de atendimento escolar e da ampliação das relações humanas, a atenção dada ao aprendiz está diretamente relacionada ao emocional, aos aspectos psicológicos, sociais, pedagógicos, culturais, assim como aos fatores físicos internos e externos.

\footnotetext{
${ }^{2}$ Esse documento foi alterado para o Decreto ${ }^{\circ}$ 10.502, de 30 de setembro de 2020. Institui a Política Nacional de Educação Especial: Equitativa, Inclusiva e com Aprendizado ao Longo da Vida. (Brasil, 2020, p. 01).
} 
Tal atenção não se restringe apenas ao ambiente escolar, mas também ao familiar e ao comunitário. Vale dizer que estes fatores acabam interferindo no processo da aprendizagem. Visto que os estudos teóricos demonstram a preocupação com o processo de aprendizagem e com o aprimoramento dos estudos surge, então, a Psicopedagogia. Mas, o que é Psicopedagogia?

Segundo a Associação Brasileira de Psicopedagogia Abpp, art. $1^{\circ}$ :

É um campo de atuação em Educação e Saúde que se ocupa do processo de aprendizagem considerando o sujeito, a família, a escola, a sociedade e o contexto sócio-histórico utilizando procedimentos próprios, fundamentados em diferentes referenciais teóricos distintos, que convergem para o atendimento dos sujeitos e sistemas que aprendem e sua forma de aprender (Abpp, 2019, p. 01).

Neste campo de atuação, o profissional Psicopedagogo tem como foco o processo da aprendizagem na área cognitiva, social, cultural e afetiva. Seu papel social é contribuir para eliminar as barreiras das dificuldades de aprendizagem realizando acompanhamento educacional, com o intuito de proporcionar respostas aos problemas subjetivos de cada indivíduo no ambiente educacional. Dessas acepções, Oliveira (2009) ressalta que:

[...] o meio cultural ao qual pertence o sujeito lhe impõe situações que são por ele transformadas, algumas em bens pedagógicos. A concepção de aprendizagem pode ser conceituada como uma construção que nasce da interação de aspectos estruturais ou cognitivos e energéticos ou afetivos, reagindo num determinado contexto social, tornando-se um processo específico e individualizado, constituindo a modalidade de aprendizagem, ou seja, o jeito de aprender de cada um (Oliveira, 2009, p. 14).

Na modalidade de aprendizagem, o objeto de estudo da Psicopedagogia é atuar sobre o aprendizado e verificar como o sujeito aprende. Considera que cada um aprende de uma forma específica e sempre são aprendidas habilidades novas, principalmente na fase escolar. Para o Psicopedagogo, os conhecimentos sobre desenvolvimento cognitivo, sobre aprendizagem e dificuldades específicas de aprendizagem são imprescindíveis.

Dessa forma, é necessário que esse profissional intervenha sobre as estratégias de ensino, observe o meio cultural pertencente ao sujeito, o local em que se desenvolve e modifica-se conforme ocorrem às transformações em seu entorno e em cada ambiente social que frequenta ou em que está inserido.

Cabe dizer que a escola é uma parte desse processo e que necessita compreender a cultura que envolve os sujeitos. Visca (s/d, p. 01), em entrevista à página do site do CEP - Centro de Estudos Psicopedagógicos, quando perguntado: "Que papel a escola desempenha no processo de aprendizagem?”3

No creo que el aprendizaje se restrinja a la escuela. Sí creo que la escuela es una de las mejores formas de promover algunos aprendizajes, pero el aprendizaje no sólo ocurre en la escuela. El aprendizaje se produce en el sujeto. La cultura selecciona algunos bienes culturales y los transforma en bienes pedagógicos en el sentido de que son los reactivos de conducta o estímulos para hacer que las personas ingresen en la cultura. Pero se aprende en las situaciones más diferentes. Para una persona, el aprendizaje abre el camino de la vida, del mundo, de las posibilidades, hasta de ser feliz (Visca, n/d, p. 01).

Pelo fato da aprendizagem não ser restrita às escolas, tais afirmações vêm ao encontro de que a cultura é formada, primeiramente, por indivíduos que têm suas responsabilidades no cenário escolar da prática pedagógica e em segundo lugar, o sujeito que nasce nessa cultura de aprendizagens da vida e se desenvolve por meio da sistematização dos assuntos e da

\footnotetext{
${ }^{3}$ Não acho que o aprendizado seja restrito à escola. Eu acredito que a escola é uma das melhores maneiras de promover alguma aprendizagem, mas a aprendizagem não acontece apenas na escola. A aprendizagem ocorre no assunto. A cultura seleciona alguns bens culturais e os transforma em bens pedagógicos, no sentido de que eles são os reagentes ou estímulos comportamentais para fazer as pessoas entrarem na cultura. Mas você aprende nas mais diferentes situações. Para uma pessoa, o aprendizado abre o caminho da vida, do mundo, de possibilidades, até de ser feliz (Visca, n/d, p. 01, tradução nossa).
} 
mediação dos responsáveis.

Com isso, torna-se curioso conhecer como a Psicopedagogia chegou até a instituição escolar. Segundo Oliveira (2009), o objeto de estudo da psicopedagogia volta-se diariamente para uma ação preventiva e de acolhida, percebeu-se que é importante conhecer a ação anterior ao aparecimento dos problemas encaminhados à clínica.

O reconhecimento da necessidade de uma ação preventiva no ambiente escolar antecede compreender, com base em Facci (2004), a importância do papel social da escola e da família levando em consideração esta transição na perspectiva grupal da seguinte forma:

No período pré-escolar, o que se constata é que as necessidades básicas da criança são supridas pelos adultos, e as crianças sentem sua dependência com relação a eles. O seu mundo divide-se em dois círculos: um criado pelos pais ou pelas pessoas que convivem com elas, sendo que essas relações determinam as relações com todas as demais pessoas; o outro grupo é formado pelos demais membros da sociedade. Portanto, a vida da criança muda muito quando ela entra na escola, onde a relação com os professores faz parte de um pequeno e íntimo círculo de seus contatos. A passagem da criança da infância pré-escolar à fase seguinte está condicionada, então, pela entrada da criança na escola e a atividade principal passa a ser o estudo (Facci, 2004, pp. 69-70).

No ambiente escolar, desde os anos iniciais, é possível observar as peculiaridades das crianças que, muitas vezes, não são observadas no cotidiano familiar e sim, no espaço coletivo da escola. Nesse espaço está inserido o profissional psicopedagogo que atua numa linha preventiva e/ou terapêutica e esse profissional está presente em: Clínica Psicopedagógica; Instituição Escolar; Instituição Hospitalar e Empresarial.

Seja qual for o espaço para o atendimento, esse profissional tem como uma das primeiras tarefas: o resgate da autoestima do educando, depois entrevistá-lo, escutá-lo e desenvolver análise e direcioná-lo, de forma a criar um relacionamento com o aprender. Existem a demanda particular e a institucional que buscam este profissional para a prevenção ou resgate de conteúdos não consolidados pelo aluno.

Ainda de acordo com Grassi (2009), "Diante da demanda por soluções para esses problemas, a psicopedagogia foi aos poucos consolidando e, ao mesmo tempo, foram se delineando em suas áreas de atuação e seus enfoques: respectivamente, área clínica e institucional e enfoque preventivo e terapêutico" (Grassi, 2009, p. 16).

Para a busca de encaminhamentos voltados a esses problemas de aprendizagem, o Psicopedagogo trabalha de forma conjunta com outros profissionais no ambiente escolar. No que tange ao papel do Psicopedagogo Institucional, Nascimento (2013, p. 01) afirma que: "O Psicopedagogo Institucional exerce suas atividades em organizações como a escola e tem como objeto de trabalho auxiliar a aprendizagem dos alunos que fracassam e/ou propor estratégias de prevenção ao fracasso escolar”.

E, nesse sentido, Camargo e Costa (2019, p. 16) acrescentam que, "A organização do trabalho é importante para desenvolver o conteúdo de forma articulada, significando-os para suscitar a curiosidade para o aprender, pois, sem ela, qualquer ação educativa tenderá ao fracasso".

É imprescindível ao profissional da educação conhecer o processo de aprendizagem e desenvolvimento do aluno. Este conhecimento proporciona à Psicopedagogia estar presente para contribuir com todos aqueles que apresentam algum tipo de dificuldade de aprendizado e possibilita que o profissional dessa área possa intervir no ambiente escolar.

Vale dizer que, nesse contexto, em suas orientações, é notória a importância da realização da flexibilização curricular, sendo este um importante caminho para o atendimento às necessidades específicas de aprendizagem dos alunos. Nesse sentido, salienta Fonseca (2014):

Os currículos das disciplinas da educação geral não podem continuar a ser somente "regulares", eles têm a obrigação de ser currículos universais ("Universal Design for Learning") livres de barreiras onde todas as crianças e jovens possam aprender sem ser excluídos por teorias de eficácia social já ultrapassadas. Os currículos da educação em geral 
devem ser desenhados para satisfazer a neurodiversidade e a diferenciação da aprendizagem de todos os diferentes estudantes, especialmente os que estão nas margens, e não apenas concebê-los ou validá-los para os alunos ditos regulares (Fonseca, 2014, p. 18).

Ao reconhecer que as dificuldades estão presentes nos sistemas de ensino, cabe aos profissionais da educação elaborar propostas adaptadas de currículo, o que compete à conscientização de todos os envolvidos para a flexibilização chegar à sala de aula e, de fato, prevalecer o papel social da escola no oferecimento educacional inclusivo.

Atuando no processo de intervenção nas atividades escolares e na busca constante do aprendizado, o Psicopedagogo, de forma organizada, é responsável por atender às expectativas de todos os participantes no processo de aprendizagem, despertando a motivação e mantendo sempre o olhar voltado para a subjetividade do aprendiz, com o intuito de atuar sobre as dificuldades de aprendizagem, que também percorrem no mesmo sentido.

A partir dessa reflexão é fundamental e vital que o professor tenha a consciência do trabalho do Psicopedagogo Institucional e reconheça que não é um trabalho isolado. Ele parte do trabalho com a equipe pedagógica ofertando atendimento à demanda dos educandos que necessitam de um olhar que compreenda suas dificuldades de aprendizado, oriundas, muitas vezes, de situações externas aos próprios alunos.

Desta forma, facilitará sua compreensão e a construção do seu trabalho. Sendo assim, “[...] o principal dever do professor é sempre pensar em desenvolvimento da inteligência dos alunos" (Piazzi, 2015, p. 123). O cerne do atendimento e da possibilidade é a compreensão que todas as crianças podem aprender com ou sem dificuldades específicas, apresentando a deficiência ou não.

O que difere um ou outro tipo do aprender são os recursos metodológicos a serem utilizados e a mediação pedagógica, por meio da organização do ensino e intervenções necessárias.

\subsection{Psicopedagogia institucional e os transtornos funcionais específicos (TFE)}

Os TFE compõem o ambiente escolar inclusivo, no estado do Paraná faz parte do público alvo da Educação Especial, caracterizando as dificuldades específicas de aprendizagem ou distúrbios de aprendizagem (como já foram assim identificados e ainda são, muitas vezes), advindos de queixas que precisam ser verificadas como, por exemplo: acessibilidade pedagógica, contexto familiar, bullying, dificuldade de aprendizagem, entre outras.

Estão presentes no ensino regular dentro do projeto de escola única. A amplitude da concepção de inclusão deu-se a partir da Declaração de Salamanca de 1994, documento que trata da escola inclusiva e delibera a respeito de Princípios, Políticas e Práticas na Área das Necessidades Educativas Especiais. Desta forma, em destaque um dos seus proclames:

Escolas regulares que possuam tal orientação inclusiva constituem os meios mais eficazes de combater atitudes discriminatórias criando-se comunidades acolhedoras, construindo uma sociedade inclusiva e alcançando educação para todos; além disso, tais escolas provêem uma educação efetiva à maioria das crianças e aprimoram a eficiência e, em última instância, o custo da eficácia de todo o sistema educacional (Unesco, 1994, p. 01).

Dentre essas conquistas inclusivas, o combate a atitudes discriminatórias é a mais importante que se pode fazer menção e está presente no documento subsidiário da PNEEPEI (2008). Sendo assim, observou-se em Glat e Nogueira (2003) a seguinte constatação:

Para que a inclusão de alunos com necessidades especiais no sistema regular de ensino se efetive, possibilitando o resgate de sua cidadania e ampliando suas perspectivas existenciais, não basta à promulgação de leis que determina a criação de cursos de capacitação básica para professores, nem a obrigatoriedade de matrícula nas escolas da rede pública. Estas são sem dúvida, medidas essenciais, porém não suficientes (Glat \& Nogueira 2003, p. 07). 
Sob o olhar da perspectiva humana e consciente, o Psicopedagogo atua para estimular a construção de conhecimento e propiciar autonomia do sujeito em seu meio. Assim, entende-se as postulações de Soares et al. (2017, p.01) que afirmam que o psicopedagogo "estimula o desenvolvimento de relações interpessoais, o estabelecimento de vínculos, a utilização de métodos de ensino compatíveis com as mais recentes concepções a respeito desse processo. Procura envolver a equipe escolar, ajudando-a a ampliar o olhar em torno do aluno e das circunstâncias de produção do conhecimento".

É essencial que a mediação dos profissionais da educação crie possibilidades e estímulos que propiciem a aprendizagem e o desenvolvimento de todos. Conhecer as barreiras impostas e compreendê-las é o que fornece elementos para dirigir esta atividade de forma consciente no processo educacional. Ressalta Fonseca (2014) que:

Da mesma forma, os currículos das várias disciplinas escolares não devem ser concebidos e implementados só para alunos regulares, eles devem ser construídos e implementados numa dimensão universal inclusiva, ou seja, também para alunos com diferenças e preferências de aprendizagem onde os currículos não exagerem as suas dificuldades, mas que disponham de apoios ou suportes ("scaffoldings") "andaimes" que os permitam superar (Fonseca, 2014, p. $18)$.

Para a conscientização da construção do currículo como forma de superação é importante destacar, contudo, dois pontos relevantes: o olhar em torno do aluno, a observação das circunstâncias que envolvem a aprendizagem e uma escuta apurada, além da importância dos currículos serem construídos e implementados sob uma visão universal inclusiva.

Este olhar leva em consideração as especificidades dos sujeitos que foram identificados com TFE. Os TFE, como já definidos, são grupos heterogêneos de alterações manifestadas por dificuldade de aprendizagem, à forma como o indivíduo processa a informação e o distúrbio de aprendizagem numa perspectiva intrínseca e extrínseca do sujeito.

Devem ser levados em consideração esses conhecimentos pelos profissionais para compreenderem as capacidades cognitivas de cada sujeito. Este público é considerado pertencente à Educação Especial (EE), no Estado do Paraná e podem ser inseridos e trabalhados em Salas de Recursos Multifuncionais (SRM), no contraturno.

\subsection{Aspectos legais a partir da PNEEPEI- 2008}

Hoje, no Brasil, está estabelecida a PNEEPEI (2008) como meio de proporcionar uma educação de qualidade para todos os alunos. Tem como propósito guiar os sistemas educacionais para organização dos serviços e recursos da EE de forma complementar ao ensino regular, sendo obrigatório no sistema regular de ensino. Este documento também define a oferta do AEE, em todas as etapas, níveis e modalidades. A PNEEPEI (2008) postula assegurar a inclusão escolar de alunos com deficiências, transtornos e altas habilidades/superlotação, bem como orientar os sistemas de ensino para garantir: acesso ao ensino regular, com participação, aprendizagem e continuidade nos níveis mais elevados do ensino.

Este documento também, "considera alunos com deficiência aqueles que têm impedimentos de longo prazo, de natureza física, mental, intelectual ou sensorial, que podem restringir sua participação plena e efetiva na escola e na sociedade" (Brasil, 2008, p. 15). O encaminhamento das políticas públicas inclusivas em EE, no Estado do Paraná, traz definição e caracterização sobre os TFE e os considera como parte integrante da EE e de programas de atendimentos específicos.

Os TFE não constam nas políticas nacionais como fazendo parte da EE. Sendo assim, o Estado do Paraná institui a Deliberação 02/ 2016 e a Instrução 07/2016 e de 2018, no qual definem os TFE da seguinte maneira: “[...] referem-se à funcionalidade específica (intrínsecas) do sujeito, sem o comprometimento intelectual [...]. O objetivo da instrução é apoiar as instituições de ensino, complementando a escolarização dos estudantes [...]” (Paraná, 2016b, p. 02).

Os documentos legais citados dispõem sobre o atendimento destinado aos educandos com TFE assegurando-lhes o AEE com programas de enriquecimento curricular, o ensino de linguagens e códigos específicos de comunicação e sinalização, ajudas técnicas e tecnologia assistiva, entre outros. É importante ressaltar que: 
No Estado do Paraná, em cumprimento aos preceitos legais e às recomendações de documentos nacionais e internacionais, que destacam diretrizes para a construção de espaços educacionais inclusivos, a oferta de serviços de apoio complementar e suplementar especializados, nas escolas da rede pública de ensino, para o público-alvo da Educação Especial, é acrescido do atendimento aos alunos com transtornos funcionais específicos, organizado na de SRM, Professor de Apoio à Comunicação Alternativa (PAC), Professor de Apoio Educacional Especializado, (PAEE) e Tradutor e Intérprete de LIBRAS (TILS), Guia Intérprete e Professor Itinerante (Paraná, 2014, p. 02).

Além do AEE em espaços educacionais inclusivos, a Instrução nº 07/2016 - SEED/SUED esclarece que a avaliação para ingresso nas SRM, aos alunos com TFE, deve ocorrer por meio de avaliação pedagógica e clínica/neurológica. Fazem parte dos TFE, os distúrbios de aprendizagem: dislexia, disortografia, disgrafia, discalculia e transtorno do deficit de atenção e hiperatividade (TDA/H). E orienta em quais aspectos focar:

À aquisição da língua oral e escrita, interpretação, produção de textos, sistemas de numeração, cálculos, medidas, entre outros, bem como as áreas do desenvolvimento, acrescida de parecer de especialista em psicopedagogia e/ou fonoaudiólogo e complementada quando necessário, por psicólogo (Paraná, 2016b, p. 04).

Assim, temos a escola como local que propicia observar os aspectos dos distúrbios de aprendizagem ${ }^{4}$ que de fato aparecem e os documentos contemplam os conceitos e orientam o trabalho. As avaliações ocorrem por meio de intervenções para sondagem e diagnóstico, acrescidas de pareceres de especialistas em Psicopedagogia e/ou Fonoaudiólogo e são complementadas, quando necessário, por Psicólogo.

Daí a necessidade de conceituar estes distúrbios. Conforme pontuam os autores Capellini et al (2007):

A dislexia é caracterizada como transtorno da leitura e da escrita, que interfere no rendimento escolar, deixando-o inferior ao esperado em relação à idade cronológica do indivíduo, ao seu potencial intelectual e à sua escolaridade. Estima-se que afete em torno de 5 a $10 \%$ de escolares. Tanto o TDAH como a dislexia são condições genéticoneurológicas que podem apresentar, em sua história acadêmica, o fracasso escolar, quer seja determinado por alterações na entrada, como ocorre no TDAH ou no processamento cognitivo da leitura, como na dislexia (Capellini et al., 2007, p. 114).

Sendo assim, as possíveis intervenções que a escola promove de competências básicas para os disléxicos são: a atenção; a percepção e memória auditiva e visual; as habilidades fonológicas; a associação auditiva-visual; as noções de tempo e espaço; a expressão oral e escrita; expressão e compreensão de textos lidos; entre outras.

É de suma importância que a escola tenha estrutura para atender aos disléxicos, uma vez que esta é uma das causas da evasão escolar, como afirma Gherlandi (2016): "De difícil diagnóstico e de difícil tratamento, necessita de uma equipe multidisciplinar (psicólogos, fonoaudiólogos, psicopedagogos) [...]. Dislexia é uma das causas de evasão escolar em nosso país [...]" (Gherlandi, 2016, p. 15-16). As necessidades educacionais do público dos TFE matriculados nas escolas regulares recebem atendimento especializado nas SRM.

Outro transtorno de aprendizagem é a Disortografia. De acordo com Fernández et al (2010):

O Transtorno Específico da Escrita, também conhecido como Disortografia, é uma alteração na planificação da linguagem escrita, que causa transtornos na aprendizagem da ortografia, gramática e redação, apesar de o potencial intelectual e a escolaridade do indivíduo estarem adequados para a idade (Fernández et al, 2010, p. 02).

O caso de Disortografia, relacionado à escrita e está previsto no AEE no contraturno, por meio de equipe multiprofissional e interdisciplinar de caráter complementar e suplementar, no Estado do Paraná. O atendimento prestado pelo

\footnotetext{
4 "Os distúrbios de aprendizagem acontecem quando há uma "disfunção" no sistema nervoso central (SNC) e as informações recebidas não são processadas corretamente" (Ciasca, 2004, p. 27).
} 
Psicopedagogo aos TFE oferece oportunidades de acertos no contexto das dificuldades específicas de aprendizagem do educando.

Muitas vezes, uma das portas de entrada que desencadeia o aprendizado como abstração não está acessível, devido à falta de atenção, entre outros fatores que desencadeiam a dificuldade interpretativa quando estão diante de conteúdos de aprendizagem escolar.

Sendo assim, o Psicopedagogo procede com um trabalho diversificado acompanhando o processo de aprendizagem do aluno. Ele atua estimulando a consciência fonológica, coordenação motora, organização espacial entre outros estímulos, tomando por base o sistema educacional e a possível flexibilização curricular que visa ao desenvolvimento intelectual, ao emocional e ao social do aprendiz, de forma preventiva.

A Disgrafia é um transtorno específico da aprendizagem que se apresenta logo nos primeiros anos da vida escolar. A Disgrafia, segundo Almeida et al. (2010):

É a dificuldade relacionada à execução do grafismo, existindo uma falta de regularidade e mau controle da escrita. A disgrafia pode acompanhar uma criança desde muito cedo, aos quatros anos já traz em si uma performance no traçado, e já é possível fazer o diagnóstico (Almeida et al., 2010, p. 08).

A Disgrafia tem como uma de suas características a dificuldade na grafia. "A Disgrafia, também chamada de letra feia, ocorre devido à criança não conseguir recordar a grafia correta da letra. Ao tentar recordar a grafia, apresenta a sua escrita muito lenta e por vezes ilegível" (Custódio \& Pereira, 2013, p. 07). O AEE, para este público, busca superar as barreiras que impedem sua desenvoltura e investiga as variações que interferem no processo de ensino e aprendizagem.

Ainda, sobre os transtornos, a Discalculia apresenta-se como um bloqueio impedindo a abstração das operações elementares. De acordo com Lopes e Pereira (2016):

A Discalculia ou transtorno específico da habilidade em aritmética (CID-10) (1993) ou transtorno da matemática (DSM-IV-TR, 2003), manifesta-se através das competências não adquiridas, ou seja, dificuldade para realizar operações elementares de adição, subtração, multiplicação e divisão, sem que isso seja resultado de um retardo mental ou de um ensino inadequado (CID-10, 1993). Com essa dificuldade, atinge cerca de 5\% da população escolar vem sendo afetada, tanto no rendimento escolar, como nas atividades cotidianas (Lopes \& Pereira, 2016, p. 14).

O AEE voltado para a Discalculia busca proporcionar uma melhora naquilo que the afeta o rendimento escolar e o social. Abre-se uma investigação juntamente com uma equipe multiprofissional e esse atendimento deve estar em sintonia com os professores da classe regular. "A dificuldade nesta área tem muito a ver com a forma como é abordada com as estratégias didáticas utilizadas para o processo de ensino e aprendizagem e as situações emocionais que afetam no desempenho" (Lopes \& Pereira, 2016, p. 13).

Por isso, cabe uma atenção maior por parte da equipe, são aprendizagens que serão executadas no meio social, evitando assim rotulação. Outro transtorno a se apresentar é o Transtorno do Déficit de Atenção com Hiperatividade (TDAH). De acordo com a Associação Brasileira do Déficit de Atenção - ABDA:

O Transtorno do Déficit de Atenção com Hiperatividade (TDAH) é um transtorno neurobiológico, de causas genéticas, que aparece na infância e frequentemente acompanha o indivíduo por toda a sua vida. Ele se caracteriza por sintomas de desatenção, inquietude e impulsividade (Abda, 2012, p. 01).

O público que possui TDAH, juntamente com os distúrbios de aprendizagem, tem acesso ao AEE sendo avaliados para ingressar na SRM. No caso do TDAH, a equipe foca o trabalho em aspectos relativos à aquisição da língua oral e escrita, 
interpretação e produção de textos, sistemas de numeração, cálculos, entre outros, como as áreas do desenvolvimento, com parecer neurológico e/ou psiquiátrico e complementada, quando solicitado, por parecer psicológico.

Em relação à medicalização para esse transtorno, de acordo com Tuleski e Eidt (2010):

O uso cada vez mais disseminado de medicamentos em crianças consideradas portadoras de TDAH, nesses últimos anos, sugere a prevalência dessa visão idealista, naturalizante e biologizante acerca da constituição do psiquismo humano. Esse tipo de tratamento é dirigido às manifestações individuais de supostas disfunções do cérebro, separadas da realidade objetiva e do contexto em que se desenvolvem (Tuleski \& Eidt, 2010, p. 124).

A partir da compreensão sobre os TFE, é possível traçar um caminho de trabalho na tentativa de romper os obstáculos, as barreiras que se apresentam, tornando essa caminhada mais prazerosa e eficaz. Essa é uma realidade presente nas instituições de ensino e vai além das políticas públicas inclusivas.

Com base nos apontamentos apresentados, esse público necessita do olhar sensível e perceptivo dos profissionais da educação. Um olhar que motive a ação de realmente fazer acontecer o aprendizado desse alunado específico e, em resposta, o desenvolvimento, de acordo com suas especificidades, de habilidades que possibilitem a autonomia.

A acolhida e o trabalho do professor em sala de aula devem ser feitos com muita responsabilidade e atenção especial para que suas intervenções educativas e a mediação pedagógica funcionem como estratégias diferenciadas que possibilitem a aprendizagem e o desenvolvimento das funções psicológicas superiores dos alunos que possuem os TFE.

\section{Discussão}

A pesquisa de campo foi empregada de forma online, em virtude do momento de distanciamento devido ao COVID19, para tanto foi encaminhado o questionário semiestruturado digitalizado e, a partir dele, obteve-se as repostas ${ }^{5}$ em relação ao atendimento oferecido pela profissional, no sentido de conhecer com maior profundidade o trabalho do Psicopedagogo no âmbito escolar. A respeito da entrevistada será mantido o anonimato, bem como será omitido o município onde trabalha.

Esta profissional tem 37 anos, é graduada em Pedagogia e pós-graduada em Psicopedagogia, atua nessa área desde 2011, em instituições de ensino municipal, nos níveis de Educação Infantil e Ensino Fundamental. No trabalho será identificado como Psicopedagoga A. Seu local de trabalho pertence à Secretaria de Educação e atua junto à equipe do Centro Municipal de Educação de Diagnóstico e Apoio à Aprendizagem. Segundo a entrevistada, o Centro de Educação de Diagnóstico e Apoio se estrutura e tem trabalhado da seguinte forma:

Para atender o corpo docente e discente da Rede Municipal de Ensino. Atualmente está constituído de profissionais nas áreas de Psicologia Escolar, Psicopedagogia, Pedagogia e Fonoaudiologia. O objetivo é de promover aos professores, profissionais da educação e estagiários cursos de capacitação, aperfeiçoamento e orientação nas áreas da Educação e especialidades, envolvendo as temáticas tais como: Transtorno do Espectro do Autismo, dislexia e transtornos funcionais específicos. Jogos Psicopedagógicos para o desenvolvimento cognitivo, consciência fonológica, relacionamento interpessoal no trabalho. A equipe do Centro Municipal de Educação também realiza orientações específicas aos professores e profissionais da educação, com visitas técnicas na escola ou CMEIs a respeito do desenvolvimento escolar e emocional dos educandos atendidos e as devolutivas das avaliações. Também realiza atendimentos individuais especializados nas áreas mencionadas para proporcionar ao educando superação de suas dificuldades escolares, bem como o desenvolvimento de sua potencialidade nos aspectos emocional, social, de linguagem e intelectual. Os profissionais do Centro Municipal de Educação também participam enquanto equipe nas decisões e discussões promovidas pela Secretaria Municipal de Educação, contribuindo com seus saberes nos planejamentos e ações que ocorrem no transcorrer do ano letivo, pensando na melhoria e qualidade da educação (Psicopedagoga A).

\footnotetext{
${ }^{5}$ As respostas enviadas pela Psicopedagoga participante da pesquisa foram reproduzidas de forma literal e encontram-se a seguir, na íntegra.
} 
Pautada na responsabilidade do seu papel como profissional e pensando na melhoria e qualidade da educação, quando perguntada a respeito do que a motivou a fazer tal especialização, sua resposta foi bem objetiva, "compreender os processos de aprendizagem e poder contribuir de forma mais eficiente". Em seguida é apresentado o relato de como a entrevistada desenvolve o seu trabalho diário:

\begin{abstract}
Meu trabalho como membro da equipe técnica da Secretaria de Educação consiste em realizar as avaliações psicoeducacionais em parceria com a psicóloga. A avaliação das dificuldades de aprendizagem no contexto escolar envolve aspectos referentes à psicologia (aspectos cognitvos e emocionais afetivos) e psicopedagógico, no Centro Municipal de Educação, que em discussões conjuntas com a equipe escolar planejam constantemente os encaminhamentos pedagógicos no atendimento ao educando. A Secretaria de Educação Estadual do Paraná norteia que o estabelecimento de ensino deve realizar avaliação, no contexto escolar, para a identificação das necessidades educacionais do aluno, realizada pelo professor, com o apoio da equipe técnico-pedagógica ou de professor especializado, podendo contar, ainda, com profissionais dos serviços especializados (internolexterno) sempre que necessário para a tomada de decisões quanto aos recursos e apoios necessários à aprendizagem. No Estado do Paraná, a avaliação psicoeducacional no contexto escolar tem sido realizada com a finalidade de orientar professores e demais profissionais da escola, tanto no direcionamento pedagógico quanto na indicação de procedimentos adequados às necessidades educacionais dos alunos com problemas de aprendizagem, público-alvo da Educação Especial e dos que apresentam transtornos funcionais específicos (TFE), bem como o encaminhamento dos alunos às SRM, quando necessário (Psicopedagoga $\mathrm{A}$ ).
\end{abstract}

Por meio dessas declarações, observa-se a articulação entre a equipe técnica e a Secretaria de Educação, juntamente com as diretrizes educacionais para o atendimento de alunos com TFE.

Quando perguntada se consegue perceber influências e contribuições de seu curso de graduação na sua prática como Psicopedagoga, ela responde que 'sim': “[...] se faz presente no cotidiano do trabalho, pois o embasamento teórico e prático adquiridos no decorrer da formação acadêmica vem contribuir para envolver família, escola e aluno em um processo coeso e eficaz”. Sob o olhar psicopedagógico se desloca o trabalho preventivo dentro e fora da sala de aula.

Desta forma, segundo a entrevistada, "[...] o trabalho preventivo ocorre através de grupos de estudos com professores e outros profissionais da educação, onde o tema trabalhado vem ao encontro da necessidade, visitas e orientações nas instituições escolares e aos responsáveis pela criança".

A esse profissional fica a incumbência de fazer o levantamento de hipóteses que dificultam o aprendizado do aluno e, para isso, utiliza-se de procedimentos diagnósticos e a realização da intervenção psicopedagógica. Assim, a entrevistada relata:

Reportando-me a minha atuação a qual é o processo de avaliação psicoeducacional, os principais instrumentos avaliativos utilizados são: ficha de referência pedagógica; ficha de interesse social; análise da produção do aluno; entrevista com pais ou responsáveis; provas de conhecimento; testes discriminação fonemática; memória; conceituação; organização sintático-semântica; jogos pedagógicos (Psicopedagoga A).

Ainda, sobre intervenção psicopedagógica e trabalho interdisciplinar, a entrevistada considera que:

Diante do enfoque da avaliação psicoeducacional, o que permeia bons resultados é refletir e discutir os processos didáticos e metodológicos, melhorando os procedimentos em sala de aula, as avaliações e planejamentos, um trabalho de equipe, em parceria com todos que fazem a escola (diretor, equipe técnica, professores, alunos, pessoal de apoio, família). Realizar orientação educacional, propor intervenções pedagógicas, valorizar novos conhecimentos, formas de aprender, avaliar e contribuir para que haja uma boa comunicação entre escola e família, sendo importante que ambos falem a mesma linguagem e trabalhem em conjunto (Psicopedagoga A).

$\mathrm{O}$ atendimento prestado por esses profissionais tem contribuído muito no processo ensino e aprendizagem e, desta forma, hoje se fazem presentes atendendo aqueles que estão em idade escolar. Importa saber como é a receptividade do 
trabalho do Psicopedagogo pela equipe pedagógica, pelas famílias e por diferentes profissionais na escola. A esse respeito a entrevistada destaca:

Diante das inúmeras dificuldades enfrentadas no cotidiano escolar o psicopedagogo tem tido abertura dentre os diferentes profissionais que compõe a equipe escolar e as famílias, visto que podemos trabalhar na área da educação orientando professores e a outros profissionais da instituição escolar para melhorar as condições do processo ensino e aprendizagem (Psicopedagoga A).

Destacou-se no decorrer do estudo a existência de desafios, sendo um deles a formação de professor. Podemos inferir com a autora Mora, (2008, p. 318) que "as estratégias curriculares e os professores treinados às vezes não são suficientes para atender alguns alunos de aulas inclusivas, que requerem a colaboração de profissionais de diversas disciplinas. "Na área da Psicopedagogia considera como desafio:

Existem muitos desafios que vamos descobrindo ao longo da atuação, alguns se modificam e outros permanecem, dentre eles vale ressaltar: a ética por parte dos envolvidos. Hoje as escolas têm um olhar receptivo ao nosso trabalho, mas ainda nos deparamos com situações conflitantes de diálogos com professores e com as famílias; entendimento da individualidade de cada aprendiz e diálogo com outros profissionais (Psicopedagoga A).

E continua apresentando sugestões de melhorias na atuação psicopedagógica: "[...] procurar estar sempre atualizado, buscando novos conhecimentos, atuar com ética, valorizar o ser humano em sua essência".

Considera-se, neste momento, a ênfase da entrevista que particulariza: "O atendimento aos TFE interfere no desenvolvimento da aprendizagem?" Segundo a entrevistada: “vários fatores podem interferir no ensino e aprendizagem, dos educandos com TFE, pois eles desencadeiam obstáculos que interferem no aprendizado, quando não tem diagnóstico e encaminhamento adequado". Não entrou em detalhes quais seriam os fatores.

Então, como ocorre o desenvolvimento da aprendizagem? Segundo Tuleski e Eidt (2010, p. 136), o desenvolvimento começa assim sendo, “[...] com o uso das funções mais primitivas, de caráter involuntário. Posteriormente, a criança passa por uma fase de treinamento, e o que era um processo natural se converte em processo cultural, mediante uma série de dispositivos externos".

Quando questionada a respeito do fracasso escolar, de como enfrentá-lo e qual deve ser o olhar atribuído à escola com relação a essa questão, a entrevistada responde:

O fracasso escolar é um assunto discutido por vários profissionais, por se tratar da sua complexidade, pois vários são os fatores que podem contribuir: relação professor e aluno, metodologia, currículo, avaliação, gestão escolar, de ordem social, emocional e cultural, dentre tantos outros. Dessa forma a escola deve olhar o aluno e professor também na individualidade e rever práticas pedagógicas e as relações estruturais (Psicopedagoga A).

Seja qual for a maneira de atender e intervir sobre as complexidades e a realidade que está diante dos profissionais de qualquer área, é fundamental também que haja um olhar humanizado a tudo e a todos que estão inseridos no contexto. Segundo Moysés e Collares (1997):

Para avaliar uma pessoa, precisa afastar os acidentes, as perturbações para poder olhar apenas sua inteligência. Isto é, precisa abstrair sua vida, seus desejos, seus sonhos, suas possibilidades concretas, enfim, sua condição de sujeito historicamente determinado; abstrai a criança para poder olhar a inteligência da criança (Moysés \& Collares, 1997, p. 81).

Perguntada sobre os TFE (dislexia, disgrafia, discalculia, disortografia e TDA/H), especificamente foi-lhe solicitado para pontuar qual o mais constante nos laudos ou queixas escolares, a resposta encaminhada foi: 
Dentre os transtornos funcionais específicos, o mais constante é TDA/H, em que as principais queixas são: falta de organização, dificuldade em manter atenção e a concentração, inquietação, fala excessivamente e a impulsividade, fatores estes que fazem com que haja um desequilíbrio entre o bom relacionamento com colegas e professores (Psicopedagoga A).

As queixas estão sempre presentes nas escolas e também nas famílias. As dificuldades específicas de aprender e suas causas diferenciadas têm proporcionado insatisfações, incompreensão e questionamentos. De acordo com Moysés e Collares (2013, p. 19), “Aprendizagem e comportamento; crianças e adolescentes. Estes são alvos preferenciais dos processos que buscam padronizar, normatizar, homogeneizar, controlar a vida. Processos que patologizam a vida.”.

Perguntou-se, diante disso para a Psicopedagoga: Quando surgem questionamentos a respeito de hipóteses e queixas referentes ao TDAH, em sua maioria se confirmam? De acordo com a entrevistada:

Quando é feita uma avaliação abrangente para eliminar outras causas, no qual inclui testes de inteligência, observação, vínculo social e emocional, habilidades compatíveis com estágio de desenvolvimento da criança verificadas a capacidade de atenção e concentração. No ambiente familiar entrevistando o responsável pela criança. No ambiente escolar com o professor e complementado com o olhar clínico de um médico especialista. Na sua maioria se confirma (Psicopedagoga A).

No tocante à avaliação que pontua um possível diagnóstico, as autoras Moysés e Collares (1997) salientam:

A premissa que fundamenta toda a avaliação é que temos acesso apenas às expressões do objeto de avaliação, geralmente de forma indireta. Isto posto, é preciso aprender a olhar. Olhar o que a criança sabe, o que ela tem, o que ela pode, o que ela gosta. Não se propõe nenhuma tarefa previamente definida, não se pergunta se sabe fazer determinada coisa, mesmo que seja empinar pipa ou jogar bolinha de gude (Moysés \& Collares, 1997, p. 85).

Outro ponto importante que cabe destacar aqui, é a questão da medicalização. Para a entrevistada: “O processo medicamentoso só deve ser ministrado quando realmente for necessário. Mas vemos que muitas crianças acabam sendo medicadas erroneamente, quando não é realizado o processo correto de encaminhamentos".

Para que haja o processo correto de encaminhamentos, os profissionais devem falar a mesma língua e devem basearse em evidências científicas e em novas teorias educacionais para que, dessa forma, não sejam co-participantes, mas sujeitos ativos desse processo. Nesse sentido, as autoras Moysés e Collares (2013) postulam:

Nesses processos de medicalização, controle e judicialização da vida, um instrumento é fundamental: os laudos. Laudos médicos, psicológicos, fonoaudiológicos, pedagógicos etc. Instrumento fundamental porque realiza a função de julgamento, condenação e sentença. Fundamental porque desvela o protagonismo dos profissionais, atuando de modo acrítico e quase de modo automático, em função de vários fatores, entre os quais devemos destacar a formação tecnicizada, regida pelo e para o mercado (Moysés \& Collares, 2013, p. 19).

Ainda referente às queixas lhe foi perguntado como o Psicopedagogo poderia e pode atuar no contexto escolar, com relação ao aluno com queixa de TDAH. Segue sua resposta:

Dentre as funções do psicopedagogo junto ao trabalho com o aluno TDAH podemos citar às estratégias para diminuir a hiperatividade e melhorar ou aumentar o tempo de concentração, estimular a autoestima do aluno, orientar o professor em como agir dentro da sala de aula e no ambiente escolar, complementado com o olhar clínico de um médico especialista (Psicopedagoga A).

$\mathrm{O}$ estudo se preocupou também com o número de crianças com laudo médico atestando distúrbios neurológicos, os quais têm aumentado muito. Os laudos, contudo, geram preconceito e, de acordo com as autoras Moysés e Collares (1992, p. 
15), "[...] o cotidiano escolar é permeado de preconceitos, juízos prévios sobre os alunos e suas famílias, que independem e não são abalados por qualquer evidência empírica que os refute racionalmente".

O que é possível dizer sobre isso? De acordo com a entrevistada, "[...] tem aumentado gradativamente os casos diagnosticados de TDAH". As autoras, Moysés e Collares (2011, p. 144) dizem que "o diagnóstico de TDAH é feito por base nos sintomas relatados pelo paciente ou seus familiares e devidamente interpretado por um especialista.

Que não há nenhum exame que de o diagnóstico. E, diante da sua experiência na área de atendimento Psicopedagógico Institucional the foi perguntado como ocorre sobre o atendimento inclusivo oferecido pelas escolas do Município. Posto isso, a psicopedagoga respondeu:

Tomando por base os últimos anos, o Município tem se destacado na área inclusiva, constatamos que muitos alunos conseguiram concluir o Ensino Médio, Ensino Superior, vagas no mercado de trabalho. O corpo docente está sempre recebendo formação continuada para atender as especificidades (Psicopedagoga A).

Encontra-se presente, em algumas instituições escolares, o Psicopedagogo. Este profissional contribui com a ampliação das relações e encaminhamentos no contexto escolar. Seu desejo é a mudança do olhar sobre as dificuldades específicas de aprendizagem/TFE, as deficiências, dentre outros. Para que ocorra essa transformação no âmbito escolar, de acordo com Tuleski e Eidt (2010):

Isso requer a implementação de mediadores instrumentais em todos os níveis da educação escolar. Esses mediadores podem e devem auxiliar no desenvolvimento das funções psicológicas, para que a criança adquira maior consciência, controle de seu comportamento e capacidade de planejamento (Tuleski \& Eidt 2010, p. 139-140).

$\mathrm{O}$ reconhecimento dessa mudança e a possibilidade de atendimento específico tornam-se preventivos para muitos educandos. É necessário conhecer diferentes formas de intervenção. Não se pode falar de Educação Especial sem pontuar a inclusão e o atendimento por meio dos aspectos legais da PNEEPEI (2008).

O AEE favorece o atendimento com profissionais especializados, mas muito ainda há de se fazer na sala do ensino regular, onde todos os educandos que necessitam de atendimento, juntamente com seus pares, devem ser trabalhados.

Há uma demanda escolar de alunos com TFE/do público alvo, que depende da contratação de Psicopedagogos, por meio de concursos públicos realizados pelos municípios. Os documentos legais não tratam do número de contratação do Psicopedagogo Institucional, nem da obrigatoriedade de tê-lo atuando nos ambientes escolares.

Com isso, vale destacar aqui que é primordial que se desenvolva um projeto de conscientização e sensibilização da necessidade de incluir esse profissional no quadro pedagógico escolar pelo gestor local.

\section{Considerações Finais}

Estamos diante de uma realidade escolar onde queixas constantes de dificuldades de aprendizagem se fazem presentes, tanto por parte dos professores quanto dos pais devido à maneira com que as crianças processam e abstraem os conteúdos escolares. Nem todos os alunos aprendem da mesma forma e ritmo, pois possuem maneiras diferentes de aprendizagem e devem ser respeitados e não negligenciados.

Entender o processo de aprendizagem e desenvolvimento escolar é imprescindível aos profissionais. Nesse sentido a atuação da Psicopedagogia Institucional ocorre no processo de aprendizagem, engloba as áreas cognitiva, social, afetiva e pedagógica. Áreas que, muitas vezes, passam despercebidas pelo professor, em salas de aula numerosas.

O profissional quando focado nessas áreas, desenvolve atividades de forma preventiva, em conjunto com outros profissionais, com intuito de realizar encaminhamentos e soluções referentes à superação de obstáculos ou barreiras da 
aprendizagem do menor, além de se criar possibilidades de como elaborar, desenvolver e aplicar trabalhos com os educandos que requerem estratégias diferenciadas no processo de aprender, devido às dificuldades específicas de aprendizagem.

Diante dos fatos constatados, por meio da entrevista com a Psicopedagoga, conclui-se que as Políticas Públicas Inclusivas do Estado do Paraná vêm sendo efetivadas no município. Estão presentes equipe de profissionais especializados nas áreas de Psicologia Escolar, Psicopedagogia, Pedagogia e Fonoaudiologia. Áreas de atuação que ofertam cursos de capacitação para os professores e estagiários com temáticas da EE e também em parceria com outros projetos ofertados na área educacional e realizam visitas técnicas nas escolas e CMEIs.

Em conjunto, a equipe participa das decisões e discussões promovidas pela Secretaria de Educação que contribui com seus saberes nos planejamentos e ações que ocorrem durante o ano letivo. Pensando na melhoria e na qualidade da educação, a equipe realiza avaliação no contexto escolar para a identificação das necessidades educacionais dos educandos. O que demonstra uma equipe engajada no que faz. A Psicopedagoga destacou também o aumento gradativo de casos de alunos com laudos e também menciona, com base nos últimos anos, que o município se destacou na área inclusiva.

Devido ao corpo docente estar quando solicitado recebendo formação continuada para atender às especificidades, a entrevistada pontuou que os desafios ou barreiras sempre existirão em qualquer área de atuação e o enfrentamento e capacitação contínua se fazem necessários. Alguns se modificam, outros permanecem.

Ela também destaca, como desafio, a ética por parte dos envolvidos e a existência de barreiras em situações conflitantes que exigem diálogo com professores, com as famílias e com outros profissionais. Além disso, salienta que há necessidade de superar os entraves na comunicação entre os envolvidos.

A entrevistada também deixa evidente que muitos desses entraves estão relacionados a mudanças de atitudes, crenças, valores, e a cultura das pessoas e afirma que, mesmo com dificuldades, ações são encaminhadas, constantemente, no convívio escolar no seu tempo e com respeito mútuo.

Cabe ao Psicopedagogo contribuir com o ambiente escolar e com todos os que nele estão envolvidos, por meio do seu olhar sistematizado e holístico. O ambiente escolar, no cumprimento do seu papel social, torna-se o meio necessário para desenvolver o meio interativo no cumprimento da legislação e do atendimento educacional inclusivo.

No tocante à conscientização dos envolvidos, cada dia está se delineando a efetivação de atitudes conscientes, conforme as condições de estrutura de trabalho que se tem hoje e a necessidade de flexibilização dos currículos para o AEE dos alunos considerados público alvo da EE.

Sendo assim, faz-se essencial a mediação pedagógica dos profissionais da educação, a qual cria possibilidades e estímulos que contribuem para o desenvolvimento e para a aprendizagem de todos.

O trabalho interdisciplinar, voltado ao público alvo, visando para a aprendizagem e o pleno desenvolvimento escolar de cada aluno, deve acontecer por meio de comprometimento das equipes envolvidas. Dessa forma, o trabalho é desafiador e otimizar o AEE torna-se necessário para o desenvolvimento das funções intelectivas do pensamento. Com isso, é primordial que o olhar da Psicopedagogia esteja presente e atento no contexto escolar, para que todas as inclusões necessárias aconteçam e tenham êxito.

\section{Referências}

ABDA, Associação Brasileira do Déficit de Atenção (2012). O que é TDAH?: https://tdah.org.br/1-o-que-e-tdah-2/.

ABPP, Associação Brasileira de Psicopedagogia (2019). Código de Ética da Psicopedagogia. http://www.saopauloabpp.com.br/codigo_de_etica.pdf. Almeida, A., Almeida, M. \& Almeida, M. (2010) Manual para o Tratamento de Disgrafia, Disortografia e Trocas de Letras. Biblioteca 24 horas.

Brasil (2008). Ministério da Educação. Secretaria da Educação Especial. Política Nacional de Educação Especial na Perspectiva da Educação Inclusiva. Brasília, DF: MEC/SEESP. Portal.mec.gov.br/index.php?option=com_docman\&view=download\&alias=16690 politica-nacional-de-educacao-especial-naperspectiva-da-educacao inclusiva $\% 2005122014 \&$ Itemid=30192. 
Brasil (2020). Ministério da Educação. Secretaria da Educação Especial. Política Nacional de Educação Especial: Equitativa, Inclusiva e com Aprendizado ao Longo da Vida. Brasília, DF: MEC/SEESP. https://www.in.gov.br/en/web/dou/-/decreto-n-10.502-de-30-de-setembro-de-2020-280529948.

Barros, E. N., Fontenele, F. E. \& Conceição, R. C (2012). Fracasso Escolar: uma breve abordagem teórica acerca das diferentes explicações. http://www.editorarealize.com.br/revistas/fiped/trabalhos/d3b96528d78a7bfc36946a04aee299bd_1911.pdf.

Camargo, J. $\quad$ S. $\quad \& \quad$ Costa, $\quad$ L. $\quad$ P $\quad$ (2019). $\quad$ Prática $\quad$ Psicopedagógica $\quad$ Institucional. $\quad$ Appris https://books.google.com.br/books?id=15qfDwAAQBAJ\&pg=PT13\&lpg=PT13\&dq=Kiguel+1990\&source=bl\&ots=qkMHNMXq0c\&sig=ACfU3U2Y6P5RU dOnL7bknweasc3q89JQw\&hl=ptBR\&sa=X\&ved=2ahUKEwjKtJjGqZHoAhXsILkGHf1 gDV8Q6AEwA3oECAgQAQ\#v=onepage\&q=Kiguel\%201990\&f=fa lse.

Capellini, S. A, Ferreira, T. L, Salgado, C. \& Ciasca, S. M (2007). Desempenho de escolares bons leitores, com dislexia e com transtorno do déficit de atenção $e$ hiperatividade em nomeação automática rápida. Rev. Soc. Bras. Fonoaudiol, 12(02), 114-119. https://www.scielo.br/scielo.php?pid=S1516$80342007000200008 \&$ script=sci_abstract\&tlng=pt.

Carvalho, R. E (1999). Educação Especial: tendências atuais. Removendo Barreiras para a Aprendizagem. Biblioteca 24 horas.

Ciasca, S. M (2004). Distúrbio de Aprendizagem: proposta de avaliação interdisciplinar. (2a ed.), Casa do Psicólogo. https://books.google.com.br/books?hl=ptBR\&lr=\&id=bKBjBR45omAC\&oi=fnd\&pg=PA13\&dq=related:ZGOF9vNjJ9MJ:scholar.google.com/\&ots=Yayamq mTjo\&sig=4bX6GR.

Creswell, J. W (2010). Projeto de pesquisa: métodos qualitativos, quantitativo e misto. (3a ed.), Artmed.

Custódio, L. A. \& Pereira, C. D (2013). Transtornos Funcionais Específicos: conhecer para intervir. SEED? http://www.diaadiaeducacao.pr.gov.br/portals/cadernospde/pdebusca/producoes_pde/2013/2013_fafipa_ped_artigo_luciane_de_andrade.pdf.

Facci, M. G. D. A. A (2004). Periodização do Desenvolvimento Psicológico Individual na Perspectiva de Leontiev, Elkonin e Vigostski. Cad. CEDES, Campinas, 24(62), 64-81, http://www.scielo.br/pdf/ccedes/v24n62/20092.pdf.

Fernández, A Y., Cervera, J. F., Cunha, V L. O. \& Batista, A. O. (2010) Avaliação e Intervenção da Disortografia Baseada na Semiologia dos Erros: Revisão de Literatura. Rev. CEFAC, 12(03), 196-209, https://www.scielo.br/pdf/rcefac/v12n3/196-09.pdf.

Fonseca, V (2014) Papel das Funções Cognitivas, Conativas e Executivas na Aprendizagem: uma abordagem neuropsicopedagógica. Artigo Especial, 31(96), http://www.revistapsicopedagogia.com.br/detalhes/62/papel-das-funcoes-cognitivas--conativas-e-executivas-na-aprendizagem--uma-abordagemneuropsicopedagogica.

Gherland, C. R. (2016). Um Novo Olhar para a Educação Inclusiva. http://www.diaadiaeducacao.pr.gov.br/portals/cadernospde/pdebus ca/producoes_pde/2016/2016_pdp_edespecial_uenp_cassiareginasouza.pdf.

Gil, A. C (2008). Métodos e Técnicas de Pesquisa Social. Editora Atlas S.A. 2008. https://ayanrafael.files.wordpress.com/2011/08/gil-a-c-mc3a9todos-etc3a9cnicas-de-pesquisa-social.pdf.

Glat, R. \& Nogueira, M. L. L (2003) Políticas Educacionais e a Formação de Professores para a Educação Inclusiva no Brasil. Caderno do Programa de PósGraduação em Educação, 10(01). https://www.metodista.br/revistas/revistasunimep/index.php/comunicacoes/article/viewFile/1647/1055.

Grassi, T. M (2009). Psicopedagogia: um olhar, uma escuta. IBPEX.

Lopes, K. G. J \& Pereira, M. R. S (2016.). Transtornos Funcionais Específicos: avaliação com os alunos do $6^{\circ}$ ano do ensino fundamental. 2016. http://www.diaadiaeducacao.pr.gov.br/portals/cadernospde/pdebusca/producoes_pde/2016/2016_artigo_edespecial_uepg_karenguisantesjoneslopes.pdf.

Marconi, M. A \& Lakatos, E. V (2002). Técnica de Pesquisa. (5a ed.), Atlas S.A.

Mora, E (2008). Psicopedagogia Infanto-Adolescente. Equipe Cultural.

Moysés, M. A. A. \& Collares, C. A. L (1992). Diagnóstico da Medicalização do Processo Ensino-aprendizagem na $1^{a}$ série do $1^{o}$ grau no Município de Campinas. $\quad$ Em Aberto, Brasília, http://portal.inep.gov.br/documents/186968/485895/Educa\%C3\%A7 \%C3\%A3o+b\%C3\%A1 sica+a+constru\%C3\%A7\%C3\%A3o+do+sucesso+escolar/48e7c4e0-acab-4901-a946-15ec70c801e0?version=1.3.

Moysés, M. A. A. \& Collares, C. A. L (1997).. Inteligência Abstraída Criança Silenciada: As Avaliações De Inteligência. Psicologia USP, 08(0L). https://www.scielo.br/scielo.php?pid=s010365641997000100005\&script=sci_arttext\&tlng=pt.

Moysés, M. A. A. \& Collares, C. A. L (2011). O Lado Escuro da Dislexia e do TDAH. https://edisciplinas.usp.br/pluginfile.php/4139770/mod_resource/content/1/O\%20LADO\%20ESCURO\%20DA\%20DISLEXIA\%20E\%20DO\%20TDAH.pdf.

Moysés, M. A. A. \& Collares, C. A. L (2013). Controle e Medicalização da Infância. Densidades. Número 1. https://revistas.ufrj.br/index.php/desidades/article/view/2456.

Nascimento, K. A. O (2013). O Trabalho do Psicopedagogo Institucional: experiência em uma escola de Teresina - PI. http://www.editorarealize.com.br/revistas/fiped/trabalhos/Comunicacao_1674.pdf.

Oliveira, M. A C (2009) Intervenção Psicopedagógica na Escola. https://docplayer.com.br/10924680-Intervencao-psicopedagogica-na-escola-mari-angelacalderari-oliveira.html.

Paraná (2014). Organização do Trabalho Pedagógico Especializado na Rede Pública Estadual de Ensino. 2014. http://www.gestaoescolar.diaadia.pr.gov.br/arquivos/File/sem_pedagogica/julho_2014/anexo7.pdf. 
Research, Society and Development, v. 11, n. 2, e47711225002, 2022

(CC BY 4.0) | ISSN 2525-3409 | DOI: http://dx.doi.org/10.33448/rsd-v11i2.25002

Paraná (2016a). Deliberação $n^{\circ}$. 02/2016 - SEED/SUED: Dispõe sobre as normas para a modalidade educação especial no sistema estadual de ensino do Paraná. http://www.cee.pr.gov.br/arquivos/File/pdf/Deliberacoes/2016/Del_02_16.pdf.

Paraná (2016b). Instrução no. 07/2016 - SEED/SUED: Dispõe critérios para o atendimento educacional especializado em sala de recursos multifuncionais SRM deficiência intelectual, deficiência física neuromotora, transtornos globais do desenvolvimento e transtornos funcionais específicos nas instituições que ofertam Educação Básica na rede pública estadual de ensino. Curitiba. http://www.educacao.pr.gov.br/sites/default/arquivos_restritos/files/documento/201912/instrucao072016sued.pdf.

Piazzi, P (2015). Ensinando Inteligência. (2a ed.), Goya.

Saviani, D (2009). Formação de Professores: aspectos históricos e teóricos do problema no contexto brasileiro. Revista Brasileira de Educação, Campinas, v. 14, n. 40. http://www.scielo.br/pdf/rbedu/v14n40/v14n40a12.pdf.

Silva, V. L. T. \& Piccolo, V. L. N. (2010). Dificuldade de Aprendizagem na Perspectiva das Inteligências Múltiplas: um estudo com um grupo de crianças brasileiras. Revista Portuguesa de Educação, 23(2). file:///D:/Downloads/1_5179525323963760753.pdf.

Soares, M., Santos, M. K. S. \& Sena, C. C. B (2017). A Contribuição do Psicopedagogo no Contexto Escolar. https://www.webartigos.com/artigos/acontribuicao-do-psicopedagogo-no-contexto-escolar/81181.

Tuleski, S. C \& Eidt, N. M (2007). Repensando os Distúrbios de Aprendizagem a partir da Psicologia Histórico-Cultural. Psicologia em Estudo, 12(03), https://www.scielo.br/pdf/pe/v12n3/v12n3a10.

Tuleski, S. C \& Eidt, N. M (2010). Transtorno de Déficit de Atenção /Hiperatividade e Psicologia Histórico - Cultural. Cadernos de Pesquisa, 40(139). file:///D:/Downloads/tULESKI\%20188-598-1-PB.pdf.

Unesco (1994). Declaração de Salamanca 1994: sobre os princípios políticas e práticas na área das necessidades educativas especiais. http://portal.mec.gov.br/seesp/arquivos/pdf/salamanca.pdf.

Visca, J. Psicopedagogía y Epistemología Convergente. [Entrevista cedida a] Graciela Rizzo. Buenos Aires. CEP - Centro de Estudos Psicopedagógicos. Jorge Visca - Psicopedagogía, Capital Federal, https://www.cepjorgevisca.com.ar/entrevistas_psicopedagogia.php. 